\title{
Direct carotid puncture for mechanical thrombectomy in acute ischemic stroke patients with prohibitive vascular access
}

\author{
*Branden J. Cord, MD, ${ }^{1}$ Sreeja Kodali, BS, ${ }^{2}$ Sumita Strander, BA, ${ }^{2}$ Andrew Silverman, ScB, ${ }^{2}$ \\ Anson Wang, BS, ${ }^{2}$ Fouad Chouairi, BS, ${ }^{1}$ Andrew B. Koo, BS, ${ }^{1}$ Cindy Khanh Nguyen, BS, ${ }^{2}$ \\ Krithika Peshwe, MBBS, ${ }^{2}$ Alexandra Kimmel, BA, ${ }^{2}$ Carl M. Porto, ${ }^{1}$ Ryan M. Hebert, MD, ${ }^{1}$ \\ Guido J. Falcone, MD, ${ }^{2}$ Kevin N. Sheth, MD, ${ }^{2}$ Lauren H. Sansing, MD, ${ }^{2}$ Joseph L. Schindler, MD, ${ }^{2}$ \\ Charles C. Matouk, MD, ${ }^{1}$ and Nils H. Petersen, MD²
}

Departments of ${ }^{1}$ Neurosurgery and ${ }^{2}$ Neurology, Yale University School of Medicine, New Haven, Connecticut

\begin{abstract}
OBJECTIVE While the benefit of mechanical thrombectomy (MT) for patients with anterior circulation acute ischemic stroke with large-vessel occlusion (AIS-LVO) has been clearly established, difficult vascular access may make the intervention impossible or unduly prolonged. In this study, the authors evaluated safety as well as radiographic and functional outcomes in stroke patients treated with MT via direct carotid puncture (DCP) for prohibitive vascular access.
\end{abstract}

METHODS The authors retrospectively studied patients from their prospective AIS-LVO database who underwent attempted MT between 2015 and 2018. Patients with prohibitive vascular access were divided into two groups: 1) aborted MT (abMT) after failed transfemoral access and 2) attempted MT via DCP. Functional outcome was assessed using the modified Rankin Scale at 3 months. Associations with outcome were analyzed using ordinal logistic regression.

RESULTS Of 352 consecutive patients with anterior circulation AIS-LVO who underwent attempted MT, 37 patients $(10.5 \%)$ were deemed to have prohibitive vascular access (mean age $[ \pm$ SD] $82 \pm 11$ years, mean National Institutes of Health Stroke Scale [NIHSS] score $17 \pm 5$, with females accounting for $75 \%$ of the patients). There were 20 patients in the DCP group and 17 in the abMT group. The two groups were well matched for the known predictors of clinical outcome: age, sex, and admission NIHSS score. Direct carotid access was successfully obtained in 19 of 20 patients. Successful reperfusion (thrombolysis in cerebral infarction score $2 \mathrm{~b}$ or 3 ) was achieved in $16(84 \%)$ of 19 patients in the DCP group. Carotid access complications included an inability to catheterize the carotid artery in 1 patient, neck hematomas in 4 patients, non-flow-limiting common carotid artery (CCA) dissections in 2 patients, and a delayed, fatal carotid blowout in 1 patient. The neck hematomas and non-flow-limiting CCA dissections did not require any subsequent interventions and remained clinically silent. Compared with the abMT group, patients in the DCP group had smaller infarct volumes (11 vs $48 \mathrm{ml}, p=0.04$ ), a greater reduction in NIHSS score $(-4$ vs $+2.9, p=0.03)$, and better functional outcome (shift analysis for 3-month modified Rankin Scale score: adjusted OR 5.2, 95\% Cl 1.02-24.5; $p=0.048$ ).

CONCLUSIONS DCP for emergency MT in patients with anterior circulation AIS-LVO and prohibitive vascular access is safe and effective and is associated with higher recanalization rates, smaller infarct volumes, and improved functional outcome compared with patients with abMT after failed transfemoral access. DCP should be considered in this patient population.

https://thejns.org/doi/abs/10.3171/2020.5.JNS192737

KEYWORDS difficult vascular access; direct carotid puncture; large-vessel occlusion; mechanical thrombectomy; acute ischemic stroke; vascular disorders

$\mathrm{F}$ IVE major randomized controlled clinical trials have established mechanical thrombectomy (MT) as a new standard of care in patients with anterior circulation acute ischemic stroke with large-vessel occlusion (AIS-LVO). ${ }^{1} \mathrm{MT}$ is typically performed via percutaneous transfemoral access. However, a subset of patients who would benefit from MT present with challenging vascular anatomy (e.g., difficult aortic arch, vessel tortuosity, stenotic vessel ostium, and iliofemoral arterial occlusive disease) that significantly slows or precludes transfemoral ac-

ABBREVIATIONS abMT = aborted MT; AIS-LVO = acute ischemic stroke with large-vessel occlusion; CCA = common carotid artery; DCP = direct carotid puncture; mRS = modified Rankin Scale; MT = mechanical thrombectomy; NIHSS = National Institutes of Health Stroke Scale; TICI = thrombolysis in cerebral infarction.

SUBMITTED October 10, 2019. ACCEPTED May 6, 2020.

INCLUDE WHEN CITING Published online August 14, 2020; DOI: 10.3171/2020.5.JNS192737.

${ }^{*}$ C.C.M. and N.H.P. contributed equally to this work. 
cess, often leading to abandonment of the procedure with attendant worse radiographic and clinical outcomes. ${ }^{2-4}$

Although alternative access routes, including transradial and transcarotid approaches, have been described as either a primary or salvage strategy, clinical series are small and outcome data are limited..$^{-10}$ We sought to compare safety and functional outcome in patients with prohibitive vascular access who 1) had aborted MT (abMT) after failed transfemoral access with those who 2) underwent attempted MT via direct carotid puncture (DCP).

\section{Methods}

We declare that all supporting data are available within the article and its online supplementary materials.

\section{Study Design and Patients}

A prospective registry of all MT cases performed at Yale New Haven Hospital (a certified Comprehensive Stroke Center) over a 3-year period (2015-2018) was retrospectively reviewed for cases of attempted MT via DCP and those who had abMT after failed transfemoral access. Demographics, medical comorbidities, site of occlusion, and presenting National Institutes of Health Stroke Scale (NIHSS) scores were obtained from the electronic medical record. All stroke management decisions, including whether or not to proceed with DCP, were made by the patients' attending providers and clinical care team in accordance with current American Heart Association guidelines. ${ }^{11}$ Two of 3 neurointerventionalists at our institution (C.C.M. and R.M.H.) started using DCP as a secondary approach for transfemoral access failure in June 2016. Thrombolysis in cerebral infarction (TICI) scores were assessed from angiograms, while final infarct volumes were calculated from follow-up MR or CT imaging. Functional outcome was assessed using the modified Rankin Scale (mRS) at discharge and 3 months.

\section{Direct Carotid Puncture Technique}

For direct carotid artery puncture access, the technique described by Mokin et al. was used, with minor modification (Fig. 1). ${ }^{12}$ The head was turned $30^{\circ}$ to the contralateral side and placed in mild extension. Using ultrasound guidance, the common carotid artery (CCA) was punctured approximately $3 \mathrm{~cm}$ above the clavicle using a $4 \mathrm{~F}$ Micropuncture Access Set (Cook Medical) in the triangle formed by the 2 heads of the sternocleidomastoid muscle and the clavicle. A $45^{\circ}$ angle of approach was favored. Under roadmap guidance, the microsheath was positioned in the external carotid artery. Over an Amplatz support wire (80-cm, Cook Medical), a 6F Brite Tip sheath introducer (5.5- or $11-\mathrm{cm}$, Cordis) was used to cannulate the CCA. An angiographic run was performed to confirm positioning of the sheath tip below the carotid bifurcation. The sheath was secured to the surrounding skin using two-point fixation.

MT was then performed in the usual fashion with a stent retriever (Medtronic Solitaire Revascularization Device) used alone or in conjunction with a distal aspiration catheter (ACE 68 or JET-7, Penumbra), the so-called Solumbra technique. The catheters were looped on the chest to facilitate handling. During each removal of the stent retriever with or without the aspiration catheter, the sheath's hemostatic valve was removed to prevent dislodgment of clot within the sheath and distal embolization. After the MT procedure was completed, the sheath was removed by manual compression or with the off-label use of a $6 \mathrm{~F}$ Angio-Seal vascular closure device (Terumo Medical). Patients were routinely kept intubated until the following day to prevent neck movement in the immediate postprocedural period. A postprocedure imaging protocol (carotid ultrasound $\times 3$ days and day 3 neck CTA) to assess for occult vascular injury or pseudoaneurysm formation was implemented later in our experience (last 8 cases).

\section{Statistical Analysis}

Baseline characteristics are summarized by mean and SD for normally distributed continuous variables, by median and IQR for skewed continuous variables, and by number $(\%)$ for categorical variables. We used chi-square, $\mathrm{t}$-, or Mann-Whitney U-tests as appropriate for unadjusted comparisons. Associations with functional outcome were analyzed using ordinal logistic regression adjusted for age and admission NIHSS score. All statistics were performed in IBM SPSS (version 24, IBM Corp.). Statistical significance was set at $\mathrm{p}<0.05$.

\section{Results}

Over the study period, 352 MT procedures were attempted, the majority via transfemoral access. In 17 cases (4.8\%), attempted MT was aborted due to an inability to reach the clot. In 20 cases (5.7\%), DCP was attempted either as a salvage technique following failed transfemoral MT $(14 / 20)$ or as a primary approach in selected cases $(6 / 20)$ when the operator believed a transfemoral approach was unlikely to succeed in a timely fashion based on review of preintervention CTA. In a single early case, we failed to introduce the sheath into the carotid artery following successful micropuncture and wire placement. Manual closure was performed. This problem likely resulted from too steep an angle of approach in a patient with a larger neck circumference (patient 20). This case was excluded from the subsequent as-treated analysis. The two groups (DCP and abMT) were well matched for known clinical predictors of outcome, including age, sex, and admission NIHSS, as well as other major medical comorbidities and location of the occlusion (Table 1). In contrast, patients with prohibitive vascular access (both the DCP and abMT groups) were overall older ( 82 vs 71 years, $p<0.001)$, were more likely to be female ( $76 \%$ vs $54 \%, \mathrm{p}=0.01)$, and had more comorbidities, including a history of prior stroke or transient ischemic attack, when compared with patients with a successful transfemoral approach from our overall AIS-LVO cohort. Patients with prohibitive vascular access were also less frequently treated with intravenous alteplase prior to endovascular thrombectomy (35\% vs $57 \%$, $\mathrm{p}=0.012$ ) and showed differences in the distribution of baseline mRS scores $(p=0.019)($ Supplemental Table 1).

Most patients undergoing DCP were intubated prior to carotid puncture (18/19). Carotid sheath removal was performed with a vascular closure device (15/19) or manual 
Cord et al.
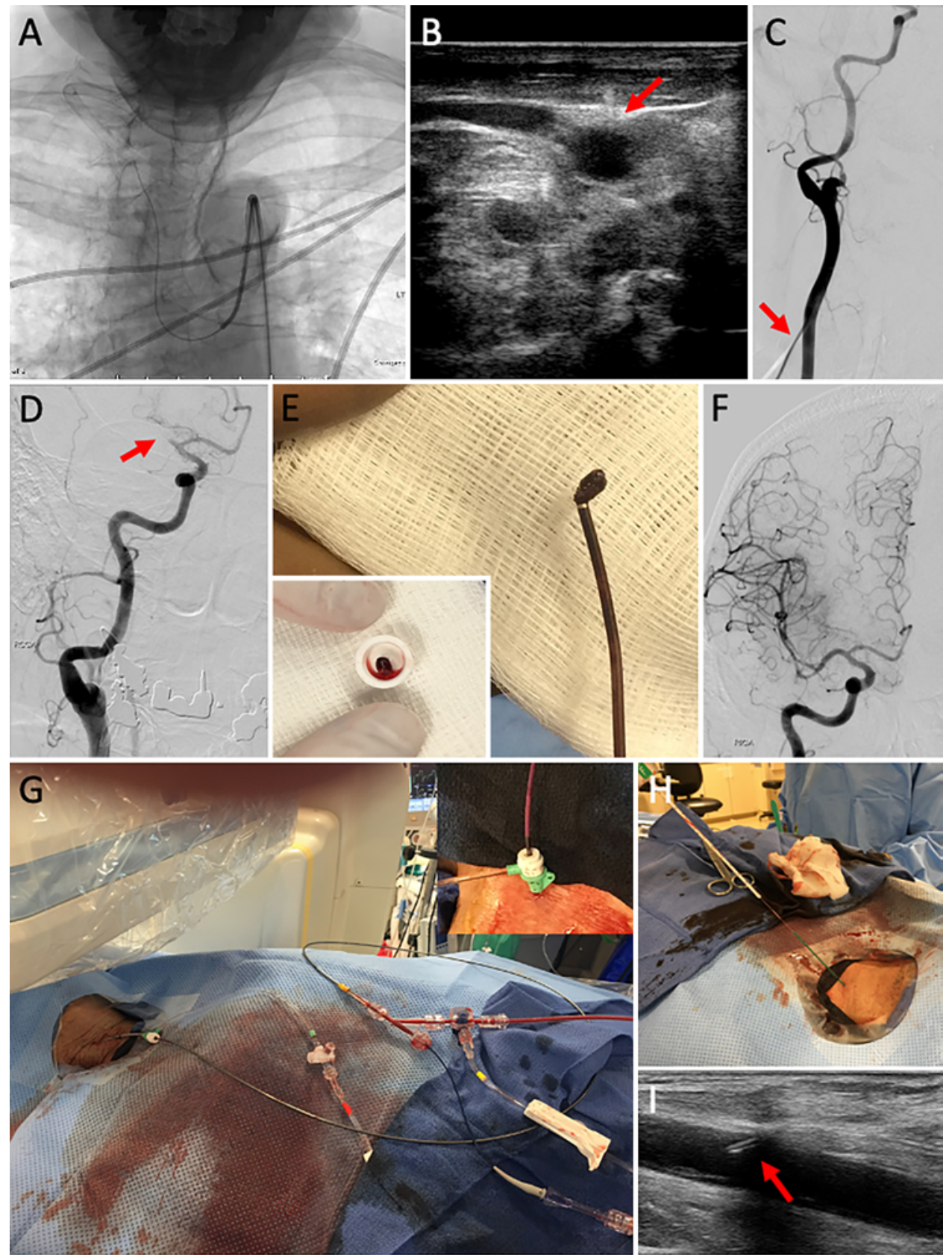

FIG. 1. Percutaneous transcarotid access for MT. A: Fluoroscopic image showing tortuous arch anatomy preventing a transfemoral approach. B: DCP is performed under ultrasound guidance (arrow indicates micropuncture needle). C: Anteroposterior digital subtraction angiogram showing that a $5.5-\mathrm{cm} 6 \mathrm{~F}$ Brite Tip sheath is inserted into the CCA. D: Anteroposterior-projection digital subtraction angiogram demonstrating large-vessel occlusion (arrow indicates right $\mathrm{M}_{1}$ occlusion). E: Corked clot (inset demonstrates how the clot can be sheared off and trapped in the sheath valve upon removal; the cap must be popped off before withdrawing the aspiration catheter). F: Anteroposterior-projection digital subtraction angiogram showing TICl grade 3 revascularization from a transcarotid approach. G: Overview of setup showing looping of long catheters outside the body; the inset shows the catheter in the carotid artery. H: Angio-Seal closure. I: Ultrasound study demonstrating the Angio-Seal footplate within the vessel without dissection or pseudoaneurysm. Figure is available in color online only.

compression (4/19). Four neck hematomas developed at the time of closure (during manual pressure hold or closure device deployment). One of the cases required treatment with fresh frozen plasma to normalize the patient's elevated international normalized ratio (warfarin). The neck hematoma remained stable in size and did not cause airway compromise. No surgical intervention was necessary. The remaining 3 cases had small-neck hematomas that were successfully managed by observation only. They did not threaten the airway, change in size over time, or require surgical evacuation or prolonged intubation. A single patient suffered a fatal delayed carotid blowout on 
TABLE 1. Demographics and baseline characteristics

\begin{tabular}{|c|c|c|c|}
\hline & abMT Group & DCP Group & p Value* \\
\hline Total no. of patients & 17 & 19 & \\
\hline Outcomes assessed at 90 days, $\mathrm{n}(\%)$ & $17(100)$ & $19(100)$ & \\
\hline Age in yrs, mean \pm SD & $83 \pm 10$ & $81 \pm 11$ & 0.677 \\
\hline Female sex, $\mathrm{n}(\%)$ & $13(76)$ & $14(74)$ & 0.847 \\
\hline Race, $\mathrm{n}(\%)$ & & & 0.575 \\
\hline White & $14(82)$ & $14(74)$ & \\
\hline Black or African American & $1(6)$ & $3(16)$ & \\
\hline Asian & $0(0)$ & $1(5)$ & \\
\hline Other & $1(6)$ & $1(5)$ & \\
\hline \multicolumn{4}{|l|}{ Medical history, n (\%) } \\
\hline Hypertension & $13(76)$ & $13(68)$ & 0.590 \\
\hline Coronary artery disease & $6(35)$ & $5(26)$ & 0.559 \\
\hline Myocardial infarction & $3(18)$ & $1(5)$ & 0.238 \\
\hline Hyperlipidemia & $7(41)$ & $8(42)$ & 0.955 \\
\hline Chronic heart failure & $2(12)$ & $4(21)$ & 0.455 \\
\hline Atrial fibrillation & $10(59)$ & $11(58)$ & 0.955 \\
\hline Diabetes mellitus & $3(18)$ & $2(11)$ & 0.537 \\
\hline Obesity & $3(18)$ & $4(21)$ & 0.797 \\
\hline Past ischemic stroke/TIA & $6(35)$ & $4(21)$ & 0.341 \\
\hline Current/past smoker† & $9(53)$ & $6(32)$ & 0.229 \\
\hline Side of occlusion, $\mathrm{n}(\%)$ & & & 0.709 \\
\hline $\mathrm{Lt}$ & $10(59)$ & $10(53)$ & \\
\hline $\mathrm{Rt}$ & $7(41)$ & $9(47)$ & \\
\hline Location of occlusion, $\mathrm{n}(\%)$ & & & 0.166 \\
\hline M1 segment & $7(41)$ & $11(58)$ & \\
\hline M2 segment & $6(35)$ & $3(16)$ & \\
\hline $\mathrm{tICA}$ & $2(12)$ & $5(26)$ & \\
\hline Tandem & $2(12)$ & $0(0)$ & \\
\hline Admission NIHSS score, median (IQR) & $17(13.5-21.5)$ & $18(14-21)$ & 0.693 \\
\hline ASPECTS, median (IQR) & $8.5(7-10)$ & $9.5(8-10)$ & 0.313 \\
\hline Preadmission mRS score, median (IQR) & $1(0-2)$ & $0(0-1)$ & 0.162 \\
\hline Treated w/ alteplase, n (\%) & $6(35)$ & $7(37)$ & 0.923 \\
\hline Onset to MT in mins, mean \pm SD & $396 \pm 291$ & $623 \pm 578$ & 0.021 \\
\hline MT to reperfusion in mins, mean \pm SD & NA & $\begin{array}{l}\text { Primary: } 40 \pm 29 \text {; secondary: } \\
\quad 130 \pm 66\end{array}$ & \\
\hline Successful recanalization, $\mathrm{n}(\%)$ & $0(0)$ & $16(84)$ & $<0.001$ \\
\hline \multicolumn{4}{|l|}{$\mathrm{TICl}$ score, $\mathrm{n}(\%)$} \\
\hline 0 & $17(100)$ & $1(5)$ & \\
\hline 1 & $0(0)$ & $0(0)$ & \\
\hline $2 a$ & $0(0)$ & $2(11)$ & \\
\hline $2 b$ & $0(0)$ & $10(53)$ & \\
\hline 3 & $0(0)$ & $6(32)$ & \\
\hline In-hospital mortality, n (\%) & $6(35)$ & $5(26)$ & 0.559 \\
\hline 90-day mortality, n (\%) & $13(77)$ & $10(53)$ & 0.137 \\
\hline
\end{tabular}

ASPECTS = Alberta Stroke Program Early CT Score; NA = not applicable; $\mathrm{TIA}=$ transient ischemic attack; tICA = terminal internal carotid artery.

${ }^{*}$ Comparison between the abMT group and DCP group (significance set at $p<0.05$ ).

$\dagger$ There were 3 patients without smoking usage data in the abMT group and 2 patients without smoking usage data in the DCP group. 


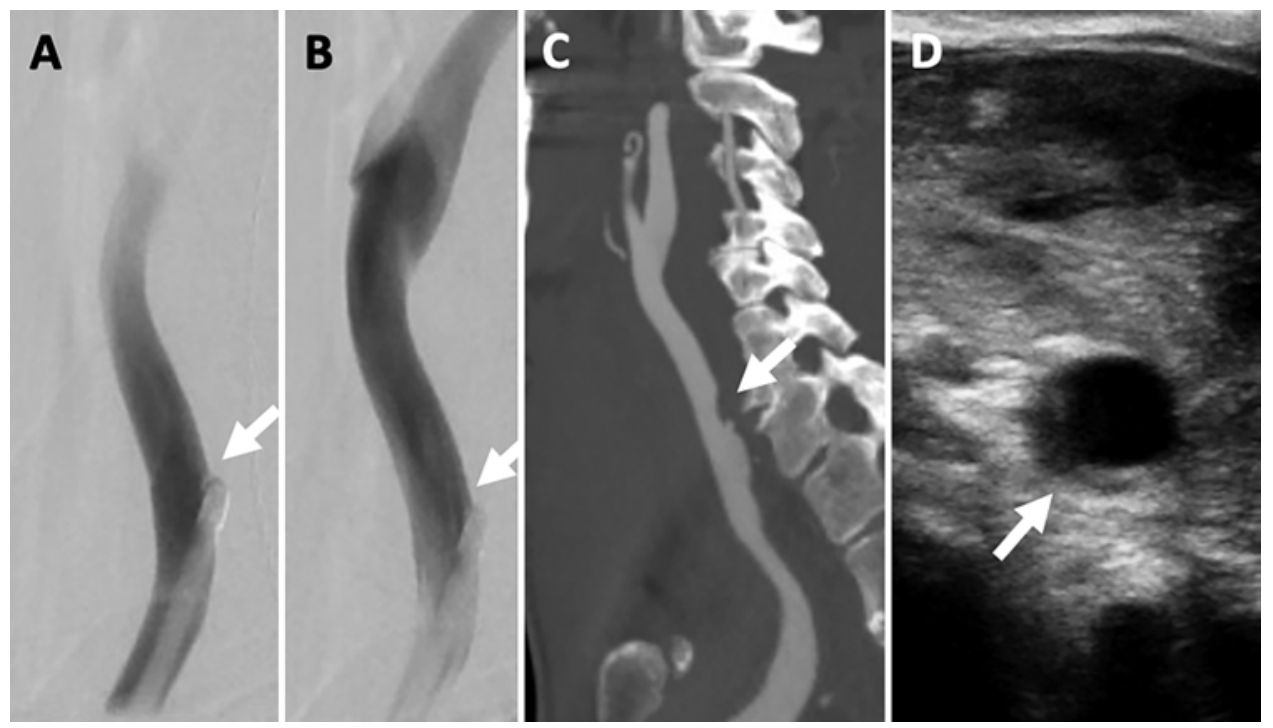

FIG. 2. Non-flow-limiting carotid dissection. A and B: Sequential frames of the right CCA angiogram. The arrows denote the tip of the carotid sheath buried into the back wall of the vessel and associated small dissection. C: Postprocedure CT angiogram showing new back wall vessel irregularity at the area of the sheath tip (arrow), with only mild narrowing of the vessel. D: Postprocedure transverse ultrasound study showing thrombus in the small dissection flap (arrow).

post-DCP day 4 following successful revascularization. In this patient, carotid sheath removal was performed with an Angio-Seal vascular closure device. Two non-flow-limiting dissections on the back wall of the CCA were noted on surveillance imaging, correlating with the position of the tip of the carotid sheath (but not the point of access into the carotid artery) during the procedure (Fig. 2). No additional interventions were required. Clinical and procedural data for each patient can be found in Tables 2 and 3 .

Successful reperfusion (TICI score $2 \mathrm{~b}$ or 3 ) was achieved in $16(84 \%)$ of 19 transcarotid MTs compared with 0 of 17 abMTs. The time from MT start to revascularization for patients undergoing primary DCP was on average shorter $(40 \pm 29$ minutes) than that for patients receiving traditional MT via femoral access puncture at our center (69 \pm 48 minutes). Patients receiving secondary DCP after failed femoral access had a longer average revascularization time of $130 \pm 66$ minutes, as expected from the multistep approach (Table 4). At 24 hours, DCP was associated with smaller infarct volume (median 11 vs $48 \mathrm{ml}, \mathrm{p}=0.041$ ) and greater reduction in NIHSS (-4 vs $+2.9, \mathrm{p}=0.034$; Fig. 3 ). After adjusting for age and admission NIHSS score, performing DCP in patients with prohibitive vascular access was associated with an increased likelihood of shifting toward a lower (i.e., better) mRS score at 3 months (adjusted OR 5.2, 95\% CI 1.02-24.5; p $=0.048$; Fig. 4).

\section{Discussion}

A significant subset of patients with anterior circulation AIS-LVOs have prohibitive vascular anatomy, precluding timely transfemoral access to the site of intracranial occlusion. Alternative approaches, including transcarotid and transradial access, have been reported in case reports and small case series, ${ }^{12-15}$ but data comparing radiographic and clinical outcomes in patients with otherwise prohibitive vascular anatomy are lacking. In this study of 36 patients with anterior circulation AIS-LVO who underwent MT, we showed that use of a transcarotid approach compared with procedure abandonment was associated with significantly increased rates of reperfusion, greater improvement in NIHSS scores, decreased infarct volumes, and improved 3-month functional outcomes. The overall high incidence of in-hospital and 90-day mortality in both groups is likely related to the advanced patient age when compared with our cohort of AIS-LVO patients and clinical trials of MT (82 vs 71 and 68 years, respectively). ${ }^{1}$ In addition, the analyzed patients had more comorbidities and a higher degree of baseline disability and were less frequently treated with TPA.

In our cohort, transfemoral MT failed in $8.5 \%$ of patients, which is slightly higher than rates previously reported and may be a reflection of the large number of nonagenarians treated at our institution. The probability of transfemoral access failure has been shown to increase with age, with up to $20 \%$ failure in patients older than 80 years, likely due to age-related changes in the vasculature. ${ }^{2,3}$

Sheath removal and hemostasis following percutaneous transcarotid access remains a significant concern and barrier to using the technique for many practitioners, especially given the high rate of perioperative antithrombotic or thrombolytic medication. Examples of open surgical closure, manual pressure, extravascular closure devices, and intraoperative closure devices have been described in the literature. ${ }^{7,8,10,12,13,16}$ Off-label use of the Angio-Seal vascular closure device was chosen, as it is the most commonly described method with the fewest described complications. ${ }^{8,16}$ It is also our standard transfemoral closure method and therefore the technique with which we have the most familiarity and understanding of procedural 


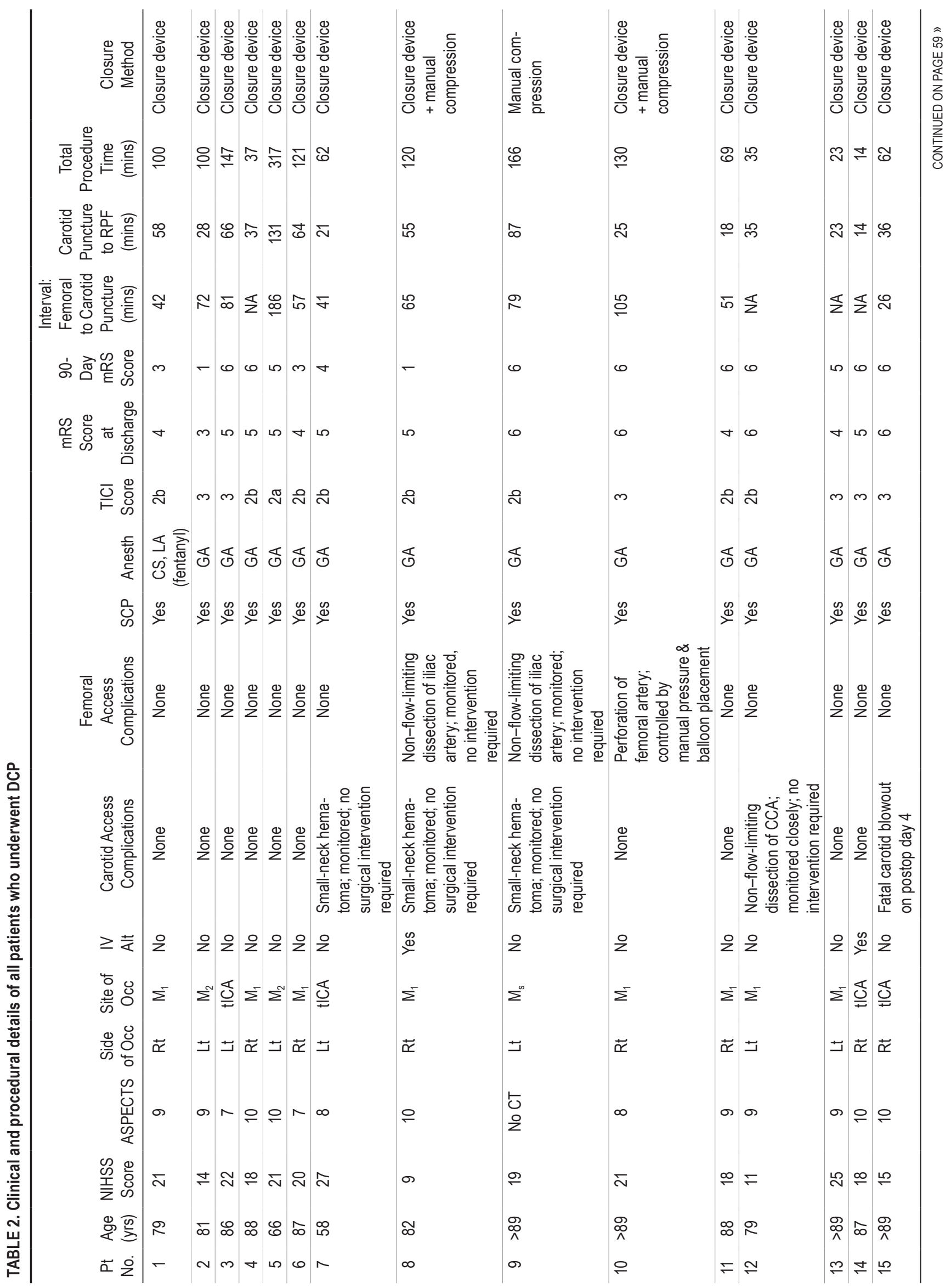




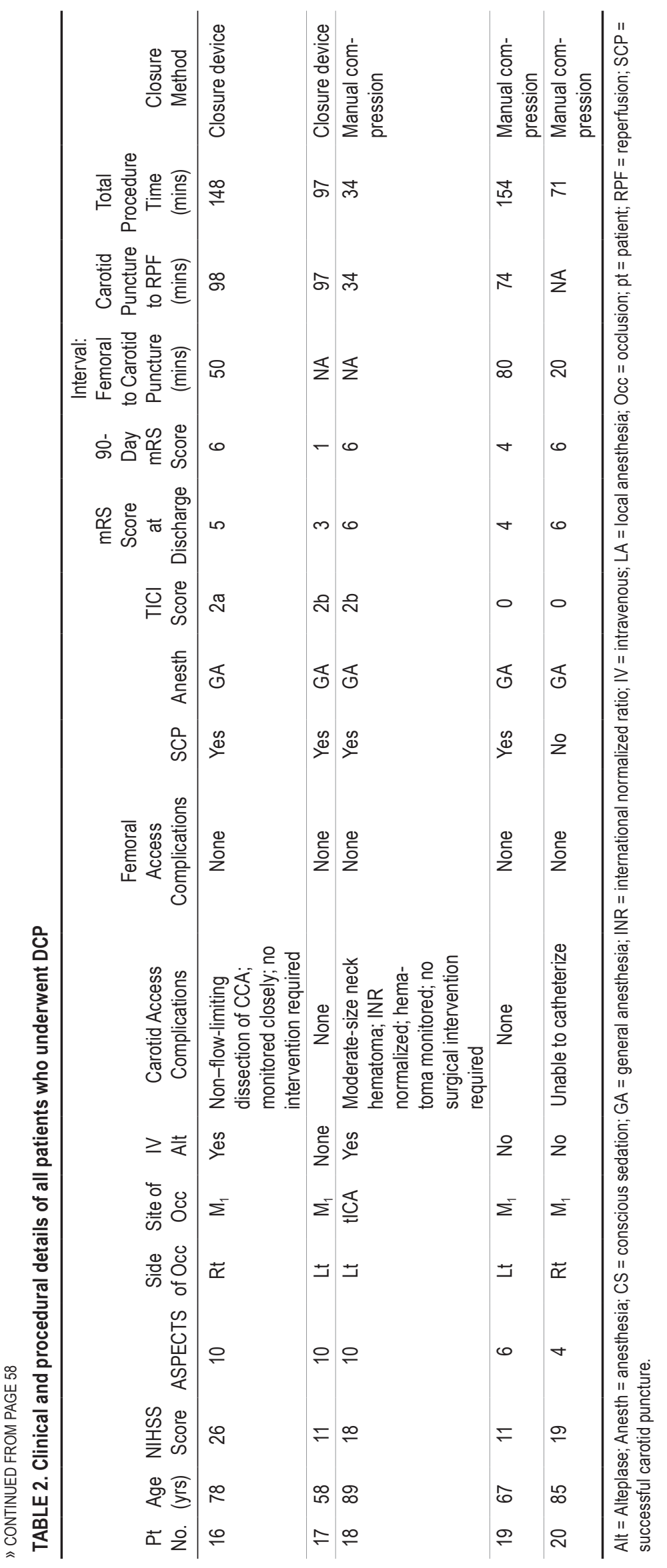




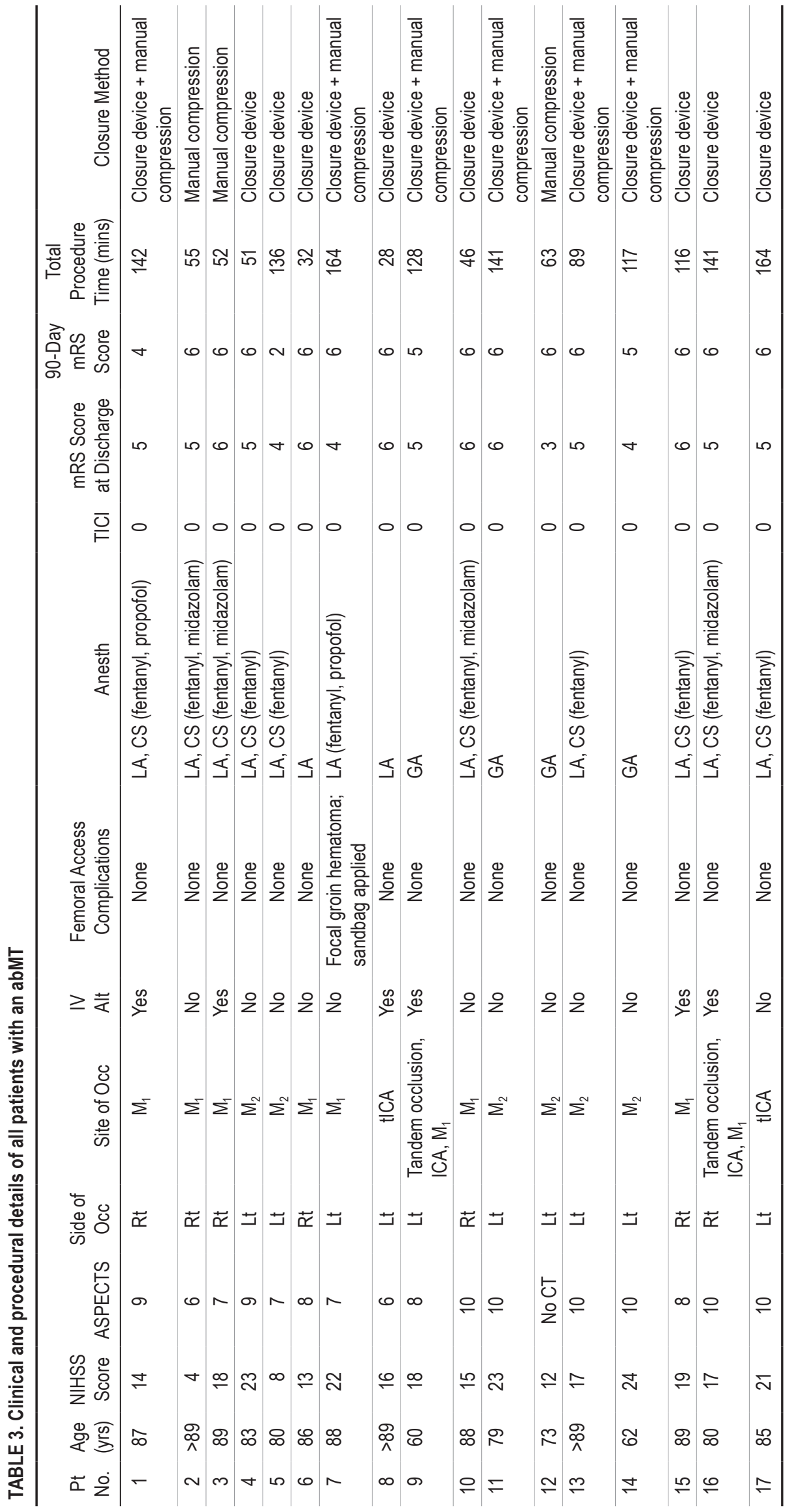


TABLE 4. Procedural time intervals for all patients

\begin{tabular}{|c|c|c|c|c|c|c|}
\hline & $\begin{array}{l}\text { Onset to EVT } \\
\text { In-Room }\end{array}$ & $\begin{array}{l}\text { EVT In-Room to } \\
\text { Femoral Puncture }\end{array}$ & $\begin{array}{l}\text { Femoral Puncture to } \\
\text { Carotid Puncture }\end{array}$ & $\begin{array}{l}\text { EVT In-Room to } \\
\text { Carotid Puncture }\end{array}$ & $\begin{array}{l}\text { Carotid Puncture to } \\
\text { Recanalization }\end{array}$ & $\begin{array}{l}\text { Groin Puncture to } \\
\text { Recanalization }\end{array}$ \\
\hline abMT (control) & $374 \pm 289$ & $22 \pm 11$ & NA & NA & NA & NA \\
\hline Primary DCP & $426 \pm 403$ & NA & NA & $37 \pm 11$ & $40 \pm 29$ & NA \\
\hline Secondary DCP & $683 \pm 644$ & $19 \pm 7$ & $68 \pm 41$ & $87 \pm 37$ & $58 \pm 33$ & $130 \pm 66$ \\
\hline MT via femoral access & $429 \pm 371$ & $26 \pm 15$ & NA & NA & NA & $69 \pm 48$ \\
\hline
\end{tabular}

EVT = endovascular therapy.

Times are reported as mean \pm SD in minutes.

nuances. Most of our transcarotid punctures were closed with an Angio-Seal device, but we have also used manual compression without major complications, even in patients who have received intravenous alteplase. Four patients developed nonsurgical neck hematomas during manual pressure hold or closure device deployment immediately after sheath removal, which were monitored. These predominantly small hematomas did not cause tracheal deviation or airway compromise and remained stable in size over time. A single patient suffered a delayed, fatal carotid blowout following successful transcarotid MT. During deployment of the vascular closure device in this latter case, puckering of the skin and soft tissue overlying the carotid artery was seen, necessitating extra manipulation of the device. This clinical course is consistent with traumatic pseudoaneurysm formation and rupture, although this could not be confirmed, as the patient's family declined a request for autopsy. Following this event, all patients treated via the transcarotid approach underwent serial daily carotid ultrasound imaging and CTA on postprocedure day 3. Note was made of non-flow-limiting dissections on the back wall of the CCA in 2 patients (this is remote from the carotid puncture site), likely due to rubbing of the tip of the 6 F sheath during the thrombectomy procedure (Fig. 1). No additional interventions were required. In our experience, increased ease of use and safety, as well as improved closure methods, could likely be obtained by the development of carotid-specific sheaths and access systems.

While a transcarotid approach was used as salvage therapy in most cases, it was also the primary access point in $32 \%$ of patients, selected with the intention of improv- ing revascularization times and outcomes. Given its relative safety and efficacy, transcarotid access for revascularization may be indicated for a larger cohort of patients with AIS-LVO. Expanding indications to reach a wider patient cohort may bring significant functional improvement to patients with fast-progressing infarcts and challenging anatomy that, while not ultimately prohibitive, can cause significantly slower transfemoral revascularization times with deleterious impacts on clinical outcomes. ${ }^{3}$ Analysis of our data demonstrates that primary DCP in patients with prohibitive anatomy achieves revascularization significantly faster compared with our entire traditional transfemoral cohort, which also includes patients with straightforward anatomy. Indeed, a predictive model for difficult transfemoral thrombectomy has recently been developed to improve patient selection based on the preprocedure CTA findings. ${ }^{4}$

Notably, transradial approaches are rapidly becoming the primary access point for neurointerventional procedures due to a lower rate of access site complications and improved ease of access in some patients with tortuous and complex arch anatomy. ${ }^{17,18}$ Increased familiarity with a transradial approach for anterior circulation large-vesselocclusion MT will likely reduce the need for a transcarotid approach. In a subset of stroke patients with difficult anatomy, a transradial first approach found equivalent clinical outcomes and revascularization times to a traditional transfemoral approach, without any major morbidity or mortality. ${ }^{6}$ Unfortunately, the small size of the radial artery may limit the consistent use of larger thrombectomy catheter systems. ${ }^{6}$ Moreover, early cross-institutional experience
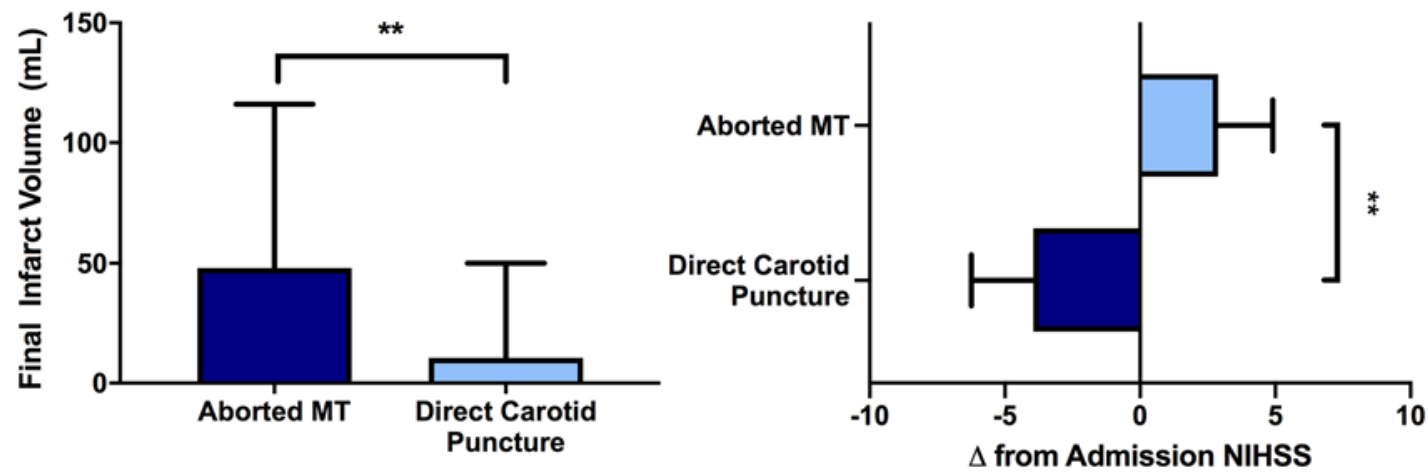

FIG. 3. Radiographic and short-term clinical outcomes. Left: Final infarct volume given in milliliters at 24 hours postprocedure. Bars and error bars represent the median and IQR, respectively. Right: Change in NIHSS score between admission and 24 hours postprocedure. Bars and error bars represent the mean and SEM, respectively. ${ }^{* *} p<0.05$. Figure is available in color online only. 


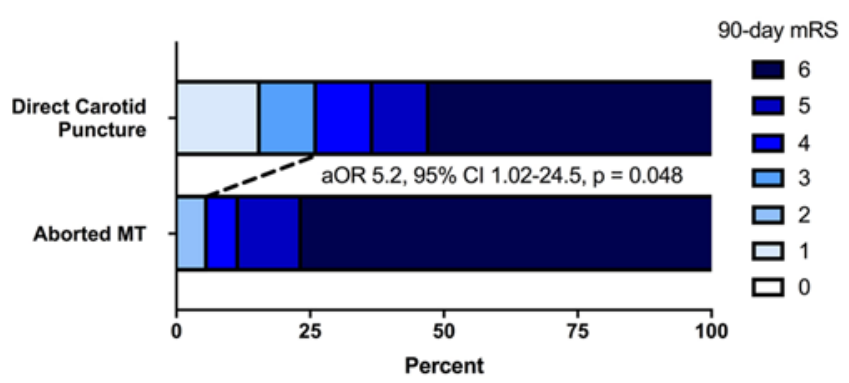

FIG. 4. Three-month functional outcomes following direct carotid puncture versus abMT; $p<0.05$ between groups. aOR = adjusted OR. Figure is available in color online only.

demonstrated an $18 \%$ failure rate of primary transradial thrombectomies, and a $6.9 \%$ conversion to a transfemoral approach. ${ }^{18}$ While increased experience and refined, transradial-specific catheter systems will improve these rates, a subset of patients will remain, in whom both transfemoral and transradial approaches are suboptimal and the most direct approach to the lesion, a transcarotid approach, may be the most clinically appropriate treatment.

Our study has several important limitations. First, the sample size was small, and while the results were significant, we were not able to adjust for all predictors of poor outcome. The addition of short-term radiographic endpoints as well as a plausible biological mechanism helps to overcome this limitation. Second, although larger than a case series, the analysis is retrospective.

\section{Conclusions}

A significant proportion of patients with AIS-LVO have anatomy prohibitive for transfemoral MT. This retrospective cohort study demonstrates that the use of transcarotid MT in these patients is associated with higher revascularization rates, smaller final stroke volumes, improved NIHSS scores, and improved functional outcome compared with the standard of care after failed transfemoral MT alone. This study supports the use of transcarotid puncture for MT.

\section{Acknowledgments}

N.H.P. receives NIH support from KL2 TR001862 from the National Center for Advancing Translational Science (NCATS). K.N.S. receives NIH support from grant nos. U24NS107215, U24NS107136, U01NS106513, and R01NR018335, and American Heart Association support from grant no. 17CSA33550004. G.J.F. is supported by the National Institutes of Health (grant nos. K76AG059992 and R03NS112859), the American Heart Association (grant no. 18IDDG34280056), the Yale Pepper Scholar Award (P30AG021342), and the Neurocritical Care Society Research Fellowship. A.S. has received funding from the American Heart Association.

\section{References}

1. Goyal M, Menon BK, van Zwam WH, et al. Endovascular thrombectomy after large-vessel ischaemic stroke: a metaanalysis of individual patient data from five randomised trials. Lancet. 2016;387(10029):1723-1731.

2. Kim DH, Kim SU, Sung JH, et al. Significances and out- comes of mechanical thrombectomy for acute infarction in very elderly patients: a single center experience. $J$ Korean Neurosurg Soc. 2017;60(6):654-660.

3. Ribo M, Flores A, Rubiera M, et al. Difficult catheter access to the occluded vessel during endovascular treatment of acute ischemic stroke is associated with worse clinical outcome. $J$ Neurointerv Surg. 2013;5(suppl 1):i70-i73.

4. Snelling BM, Sur S, Shah SS, et al. Unfavorable vascular anatomy is associated with increased revascularization time and worse outcome in anterior circulation thrombectomy. World Neurosurg. 2018;120:e976-e983.

5. Chen SH, Snelling BM, Sur S, et al. Transradial versus transfemoral access for anterior circulation mechanical thrombectomy: comparison of technical and clinical outcomes. $J$ Neurointerv Surg. 2019;11(9):874-878.

6. Haussen DC, Nogueira RG, DeSousa KG, et al. Transradial access in acute ischemic stroke intervention. J Neurointerv Surg. 2016;8(3):247-250.

7. Jadhav AP, Ribo M, Grandhi R, et al. Transcervical access in acute ischemic stroke. J Neurointerv Surg. 2014;6(9): 652-657.

8. Roche A, Griffin E, Looby S, et al. Direct carotid puncture for endovascular thrombectomy in acute ischemic stroke. $J$ Neurointerv Surg. 2019;11(7):647-652.

9. Sur S, Snelling B, Khandelwal P, et al. Transradial approach for mechanical thrombectomy in anterior circulation largevessel occlusion. Neurosurg Focus. 2017;42(4):E13.

10. Wiesmann M, Kalder J, Reich A, et al. Feasibility of combined surgical and endovascular carotid access for interventional treatment of ischemic stroke. J Neurointerv Surg. 2016; 8(6):571-575.

11. Powers WJ, Rabinstein AA, Ackerson T, et al. 2018 Guidelines for the early management of patients with acute ischemic stroke: A guideline for healthcare professionals from the American Heart Association/American Stroke Association. Stroke. 2018;49(3): $46-\mathrm{e} 110$.

12. Mokin M, Snyder KV, Levy EI, et al. Direct carotid artery puncture access for endovascular treatment of acute ischemic stroke: technical aspects, advantages, and limitations. J Neurointerv Surg. 2015;7(2):108-113.

13. Castaño C, Remollo S, García MR, et al. Mechanical thrombectomy with 'ADAPT' technique by transcervical access in acute ischemic stroke. Neuroradiol J. 2015;28(6):617-622.

14. Roche AD, Murphy B, Adams N, et al. Direct common carotid artery puncture for endovascular treatment of acute large vessel ischemic stroke in a patient with aortic coarctation. $J$ Stroke Cerebrovasc Dis. 2017;26(11):e211-e213.

15. Nishimura K, Kaku S, Sano T, et al. Direct carotid puncture for endovascular thrombectomy in a 96-year-old patient with acute cerebral infarction: a case report. Article in Japanese. No Shinkei Geka. 2018;46(9):797-802.

16. Fjetland L, Roy S. Transcarotid endovascular thrombectomy for acute ischemic stroke. J Vasc Interv Radiol. 2018;29(7): 1006-1010.

17. Kolkailah AA, Alreshq RS, Muhammed AM, et al. Transradial versus transfemoral approach for diagnostic coronary angiography and percutaneous coronary intervention in people with coronary artery disease. Cochrane Database Syst Rev. 2018;4(4):CD012318.

18. Almallouhi E, Al Kasab S, Sattur MG, et al. Incorporation of transradial approach in neuroendovascular procedures: defining benchmarks for rates of complications and conversion to femoral access. J Neurointerv Surg. Published online March 26, 2020. doi:10.1136/neurintsurg-2020-015893.

\section{Disclosures}

Dr. Sheth: equity interests in Alva Health. Dr. Petersen: grants from Novartis, Biogen, Bard, Hyperfine, and Astrocyte. 


\section{Author Contributions}

Conception and design: Petersen, Cord, Matouk. Acquisition of data: Cord, Kodali, Strander, Silverman, Wang, Chouairi, Koo, Nguyen, Peshwe, Porto. Analysis and interpretation of data: Petersen, Cord, Matouk. Drafting the article: Cord, Strander. Critically revising the article: Petersen, Kodali, Silverman, Wang, Nguyen, Peshwe, Kimmel, Hebert, Falcone, Sheth, Sansing, Schindler, Matouk. Approved the final version of the manuscript on behalf of all authors: Petersen. Statistical analysis: Petersen, Kodali, Strander, Silverman, Wang. Study supervision: Petersen.

\section{Supplemental Information}

\section{Online-Only Content}

Supplemental material is available with the online version of the article.

Supplemental Table 1. https://thejns.org/doi/suppl/10.3171/ 2020.5.JNS192737.

\section{Previous Presentations}

Portions of this work were previously presented at the 2019 CNS
Annual Meeting, San Francisco, California, October 19-23, 2019; Cord BJ, Wang A, Chouairi F, et al. Percutaneous trans-carotid puncture for mechanical thrombectomy in acute ischemic stroke patients is safe and effective: a large, single-center case series. Neurosurgery. 2019;66(suppl 1):50. http://doi.org/10.1093/neuros/ nyz310_167; and the International Stroke Conference 2019, Honolulu, Hawaii, February 6-8, 2019; Wang A, Cord BJ, Chouairi F, et al. Abstract TP15: Percutaneous transcarotid puncture is a viable alternative for thrombectomy in acute ischemic stroke patients with difficult vascular access. Stroke. 2019;50(suppl 1):ATP15. http://doi.org/10.1161/str.50.suppl_1.TP15.

\section{Correspondence}

Nils H. Petersen: Yale Medical School, New Haven, CT. nils. petersen@yale.edu. 